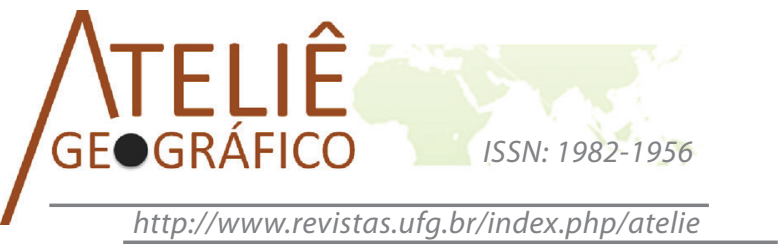

\section{O crescimento da frota de automóveis em Natal/RN e seus nexos com a produção do espaço urbano}

\author{
The Increase of Automobile Fleet in Natal/RN and its \\ connections with the production of urban space
}

\author{
El crecimiento de la flota de vehículos automotores \\ en Natal / RNy sus nexos con la producción \\ del espacio urbano
}

\author{
Francisco Fransualdo de Azevedo \\ Universidade Federal do Rio Grande do Norte \\ ffazevedo@gmail.com \\ Leonardo da Silva Galindo \\ Universidade Federal do Rio Grande do Norte \\ leonardogalindo.ufrn@gmail.com
}

\begin{abstract}
Resumo
No início do século XXI, a frota de automóveis no Brasil apresentou aumento significativo, induzindo várias transformações, em termos de infraestrutura urbana, no espaço citadino, em razão dos fluxos e problemas gerados. Assim, neste trabalho tem-se como objetivo analisar os reflexos do crescimento da frota de automóveis na produção do espaço urbano de Natal/RN, no período de 2003 a 2013, tendo em vista o crescente uso do automóvel privado e individual. Como procedimento metodológico para a construção do trabalho, realizou-se uma breve revisão bibliográfica referente à produção do espaço urbano bem como foram feitos levantamentos e consultas junto aos órgãos oficiais, como a Secretaria de Estado de Planejamento, a Prefeitura Municipal, assim como ao Instituto Brasileiro de Geografia e Estatística (IBGE) e ao Anuário da Indústria Automobilística. Os resultados da pesquisa mostram que a expansão das vias de circulação, para dar maior capacidade de fluidez aos veículos e às pessoas, em Natal, não tem sido suficiente para tornar eficaz e efetivamente fluida a acessibilidade aos distintos espaços da cidade. Nessa perspectiva, além da ampliação das vias de circulação, é necessário maior investimento por parte do poder público na melhoria da qualidade do transporte público bem como em campanhas de incentivo ao seu uso.
\end{abstract}


Palavras-chave: Automóveis. Espaço urbano. Natal/RN.

\begin{abstract}
At the beginning of 21 st century, the automobile fleet in Brazil increased significantly, inducing several transformations in terms of urban infrastructure in urbanite space, due generated problems and flows. Thus, this article has as objective to analyze the impacts of the growth of the car fleet in the production of urban space in Natal/ $\mathrm{RN}$, in the period 2003-2013, in view of the increasing use of the private car and individual. As methodological procedure for the accomplishment of the article, was performed a literature review concerning the production of urban space, as well as surveys and consultation were made on official bodies, like the Planning Secretary of State, Municipal Government just as well IBGE and Yearbook of the Automobile Industry. The results of the research show that the expansion of the traffic routes to increase the capacity for fluidity to vehicles and people in Natal has not been enough to make the accessibility more effective to different regions of the city. In view of this, in addition to expanding of roads, it is required an increased investment by the government in improving the quality of public transport, as well in campaigns as to encourage their use.
\end{abstract}

Keywords: Automobile. Urban space. Natal/RN.

\begin{abstract}
Resumen
A principios del siglo XXI, la flota de vehículos automotores en el Brasil aumentó sustancialmente, induciendo diversas transformaciones en infraestructura urbana, debido a los flujos y los problemas generados. Este texto busca analizar el crecimiento de la flota de vehículos automotores en Natal / RN y su relación con la producción del espacio urbano de 2003 - 2013, dado el creciente uso del coche privado y individual. La metodología incluye revisión de literatura sobre la producción del espacio urbano, encuestas y consultas en agencias oficiales, a ejemplo de la Secretaría de Estado de Planificación, el Ayuntamiento y sus secretarias, Instituto Brasileño de Geografía y Estadística (IBGE) y el Anuario de la Industria de vehículos automotores del país. Los resultados incluye reconocimiento de la significativa expansión de las carreteras, viaductos y túneles para proporcionar una mayor capacidad de fluidez de los vehículos automotores y personas en la ciudad de Natal. Sin embargo, a pesar de estos cambios no ha sido suficiente para la accesibilidad fácil, mobilidad satisfatório y eficácia de la infraestructura urbana generada en las distintas zonas de la ciudad. En este sentido, así como se nota la expansión de la infraestructura de carreteras, es necesario una mayor inversión por parte del gobierno en la mejora de la calidad del transporte público, con diversificación y seguridade, así como incentivo real para su mayor uso.
\end{abstract}

Palabras clave: Coches. Espacio urbano. Natal / RN.

\title{
Introdução
}

Na medida em que se reproduz socialmente, o homem produz espaço, o que leva à necessidade de se criar técnicas para produzir equipamentos, materiais e objetos úteis nesse processo. Logo, por meio das relações (políticas, econômicas, sociais, ideológicas etc.) o homem tem transformado o seu espaço e essa transformação ocorre de diferentes formas, variando conforme o estágio de desenvolvimento das forças produtivas. No modo de produção capitalista, o espaço geográfico é produzido de maneira desigual, 
o que resulta na concentração dos meios de produção, de população, do comércio e serviços e dos meios de circulação e consumo coletivos nas cidades e no seu entorno (CARLOS, 2008).

Em Natal, segundo dados da Secretaria Municipal de Meio Ambiente e Urbanismo (SEMURB, 2012 apud IBGE, 2010), o crescimento populacional tem se concentrado, principalmente, na região administrativa norte e em 2 bairros da região administrativa oeste (Planalto e Guarapes). Em 2010, o município de Natal apresentava um contingente populacional de 803.739 habitantes, já a região metropolitana possuía 1.351.004 habitantes, ou seja, aproxima-se de $43 \%$ da população total do estado do Rio Grande do Norte que, em 2010, somava 3.168.027 habitantes (IBGE, 2010). Em 2014, as estimativas do Instituto Brasileiro de Geografia e Estatística (IBGE) anunciam um contingente de 3.408.510 para o Rio Grande do Norte e de 862.044 para Natal.

O município localiza-se no litoral oriental, especificamente na região leste potiguar e se assenta, principalmente, sobre um parque dunar. Assim, a morfologia da paisagem citadina é bastante marcada pela presença de dunas, não obstante o intenso processo de verticalização em curso nas últimas décadas nesse tecido urbano. A partir dos anos 2000, Natal tem passado por um intenso processo de verticalização, concentrado em poucos bairros da cidade. Nesse sentido, A.N Santos (2014 apud Sindicato da Indústria da Construção Civil do Estado do Rio Grande do Norte, 2012), mostra como o processo de verticalização nessa cidade está concentrado espacialmente, isso com base no cadastro de alvarás emitidos para a construção em 2011 e 2012. Apenas cinco bairros (Capim Macio, Candelária, Ribeira, Lagoa Nova e Ponta Negra) foram responsáveis por $76,6 \%$ dos alvarás emitidos em 2011 e 6 bairros (Lagoa Nova, Candelária, Ponta Negra, Tirol, Ribeira e Capim Macio) por 92,98\%, em 2012.

Em estudo da SEMURB (2012) elencando apenas os edifícios construídos com mais de três pavimentos para o período de 2007 e 2013, destaca-se o bairro de Lagoa Nova, com a construção de 105 edifícios. Nesse sentido, conforme Santos (2014), o processo de verticalização aumenta a demanda por serviços e infraestruturas nos respectivos lugares em que ocorre, o que provoca a saturação da infraestrutura desses bairros.

[...] a verticalização ocorre com maior frequência nos bairros mais nobres da cidade, o que demanda um maior número de infraestrutura de acesso, saneamento básico, etc. Desse modo, essas áreas com maior presença de edifícios verticais tendem a atrair shoppings, escolas, universidades, comércios, unidades de saúde em suas proximidades (SANTOS, 2014, p. 63).

Observa-se que a verticalização soma-se ao aumento da frota de veículos como fator de pressão para o incremento da infraestrutura viária em certas áreas na cidade. Estima-se que no interior desse processo de expansão urbana de Natal, o comércio e os serviços bem como os meios de consumo coletivos continuaram concentrados em poucos bairros (Cidade Alta, Alecrim e Tirol - na Zona Leste -, Lagoa Nova, Candelária, Capim Macio e Ponta Negra - na Zona Sul).

Essa situação provoca o deslocamento diário de uma expressiva parcela da população (consumidores e/ou trabalhadores) para os bairros que concentram o maior 
fluxo e movimento no comércio, nos serviços e nos meios de consumo coletivo. Também é necessário ressaltar que parte desses deslocamentos se dá cada vez mais por meio do automóvel privado, cujo uso passou a ser fortemente estimulado tendo em vista a maior disponibilidade de crédito e a redução de impostos, a exemplo do Imposto sobre Produtos Industrializados (IPI). Tal situação tem demandado mais investimentos na ampliação/ manutenção do sistema viário e na melhoria do transporte público municipal, o que geralmente não ocorre de forma satisfatória. Nesse sentido, analisaremos os reflexos do aumento da frota de veículos na produção do espaço urbano em Natal/RN, no período compreendido entre 2003 e 2013.

Em um primeiro momento, analisaremos o crescimento da indústria automobilística brasileira entre 2003 e 2013, além do papel do Estado no estímulo ao uso do automóvel privado. Em seguida, discutiremos como o aumento da frota de automóveis demandou ampliação das vias de circulação na cidade, o que acabou levando à construção de viadutos, pontes, alargamento de várias vias, ruas e avenidas etc., que, por sua vez, contribuem para a valorização do solo urbano, com consequente aumento da renda da terra, em determinadas porções do espaço. Por fim, analisaremos o sistema de transporte coletivo municipal, constituído por ônibus, transporte alternativo (microônibus) e trens urbanos.

\section{O uso do veículo privado e o crescimento da frota de automóveis no Brasil}

A indústria automobilística configura-se como um dos principais ramos da economia nacional, responsável, em 2012, por cerca de US\$24,8 bilhões em impostos (IPI, ICMS, PIS, COFINS), tendo exportado, no referido ano, US\$ 23,4 bilhões e importado US\$ 33,2 bilhões (ASSOCIAÇÃO NACIONAL DOS FABRICANTES DE VEÍCULOS AUTOMOTORES DO BRASIL - ANFAVEA, 2014).

A importância desse vetor da economia nacional também está associada a sua capacidade de articulação com os diversos setores que compõe o circuito espacial produtivo de automóveis, o qual envolve a fabricação de aço, borracha, plásticos, componentes eletrônicos, autopeças, acessórios diversos, vendas de seguro, concessionárias, além de outros setores da economia com os quais essa indústria está relacionada, como combustíveis, estacionamentos, autoescolas etc. Convêm ressaltar que parte do significativo crescimento da indústria automobilística resulta de políticas adotadas pelo Estado, por meio do estímulo à utilização do veículo particular bem como relacionado ao fornecimento de infraestrutura, empréstimos e desconto de impostos para as montadoras (ARBIX, 2000).

Nesse sentido, o Estado, atuando como agente transformador do espaço (CORRÊA, 1989), por um lado, cria as condições necessárias para a reprodução do capital e, por outro, tem o papel de gerenciador de crises sociais (CARLOS, 2008 p. 15). Mais recentemente, com a crise financeira internacional em 2008, o Estado criou condições para a continuidade da acumulação do setor automotivo por intermédio da redução de impostos, como o IPI, somando-se ao crédito facilitado para manter a venda de veículos elevada. 
Com todos esses incentivos, a frota de automóveis no Brasil cresceu consideravelmente, aumentando 92\% entre 2003 e 2013 (DENATRAN, 2014), passando de 23.669.032 para 45.444.387. Os dados não incluem frota de ônibus, caminhões, motocicletas e outros veículos automotores. Quando se incluem todos os tipos de veículos automotores, a frota total no Brasil chega a 81.600.729, em 2013. Como resultado desse crescimento, a indústria automobilística faturou, em 2012, US\$ 93,977 bilhões, valor $94 \%$ superior ao de 2003, correspondendo a 18,7\% do PIB industrial, excetuando-se o setor de autopeças. Consequentemente, o número de habitantes em relação ao número de automóveis diminuiu de 8,4 pessoas para cada automóvel, em 2003, para 5,3, em 2012 (ANFAVEA 2014, p. 42, 144).

Por sua vez, a multiplicação no número de automóveis em circulação tem provocado transformações no espaço urbano, na proporção em que o crescimento da frota de veículos demanda ampliação do sistema viário nas cidades. Além disso, também serve aos interesses dos proprietários de solo urbano, por conseguinte, do setor imobiliário, na medida em que possibilitam o aumento do preço da terra nos locais próximos onde ocorre essa ampliação (CRUZ, 2012). Portanto, o espaço urbano "guarda o sentido do dinamismo das necessidades e dos desejos que marcam a reprodução da sociedade" (CARLOS, 2011, p. 56). Na sociedade atual, um dos principais objetos de desejo é o automóvel, que, além de diminuir o tempo de deslocamento e permitir uma suposta (falsa?) autonomia e liberdade, tornou-se um símbolo de status social.

\section{O crescimento da frota de automóveis e as transformações do espaço urbano em Natal/RN entre 2003 e 2013}

Seguindo a tendência nacional, a frota de veículos em Natal aumentou 79,25\%, entre 2003 e 2013, passando de 111.749 automóveis para 200.312. Somando-se outros veículos automotores, como ônibus, caminhões e motos, a frota municipal mais que duplicou, passando de 162.893 veículos - em 2003 - para 339.429 - em 2013 (DENATRAN, 2014). Também se deve levar em conta o crescimento da frota de veículos dos municípios vizinhos, como Parnamirim, Macaíba, São Gonçalo do Amarante e Extremoz, uma vez que muitos dos seus habitantes deslocam-se diariamente para Natal, constituindo um movimento pendular, seja para trabalhar, seja para estudar, seja para consumir uma série de serviços e uma diversidade de produtos.

Como esses deslocamentos se dão cada vez mais por meio do veículo particular, eles também contribuem para aumentar os congestionamentos nas principais vias de circulação da capital potiguar e adjacências, principalmente na BR-101, que liga Parnamirim a Natal, e nas principais avenidas desta última cidade, a exemplo das Avenidas Senador Salgado Filho/Hermes da Fonseca, Prudente de Morais, Jaguarari, Bernardo Vieira.

Também se destacam quanto à ocorrência de congestionamentos as principais vias de circulação da Zona Norte (figuras 1 a e b), que recebem os fluxos de municípios como São Gonçalo do Amarante, incluindo os fluxos oriundos do Aeroporto Internacional Governador Aluízio Alves, bem como os fluxos de Extremoz, CearáMirim e boa parte do interior do estado, somado/relacionado aos congestionamentos 
diários nas duas pontes que ligam a Zona Norte às demais regiões administrativas da cidade (figuras 2 e 3 ).

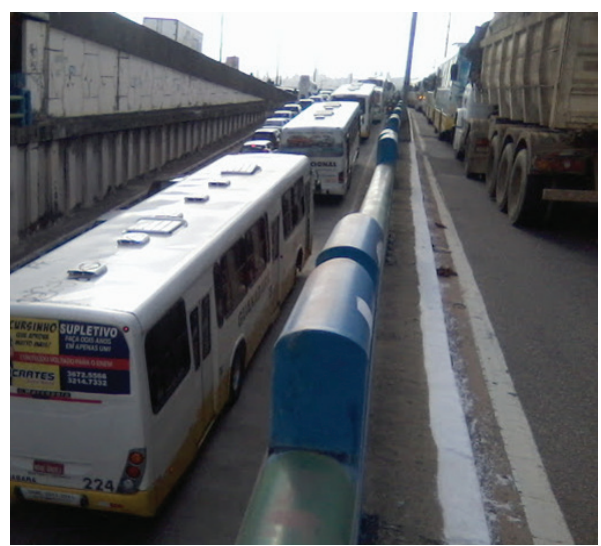

(a)

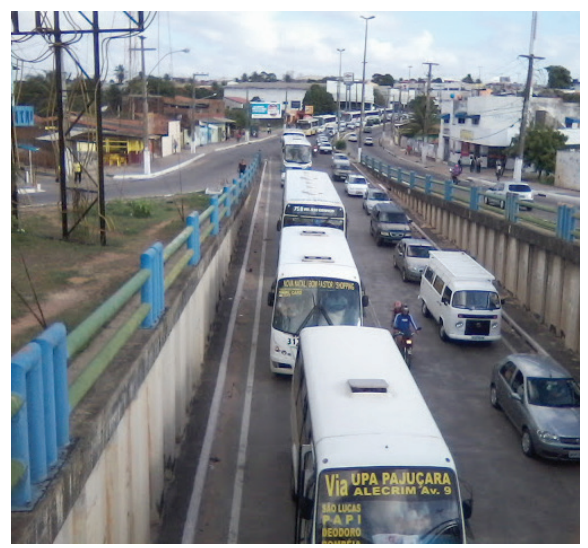

(b)

Figura 1 (a e b). Congestionamento no Complexo Viário Ulisses de Góis, bairro Igapó (Av. João Medeiros Filho).

Fonte: Acervo dos autores: 12/03/2013.

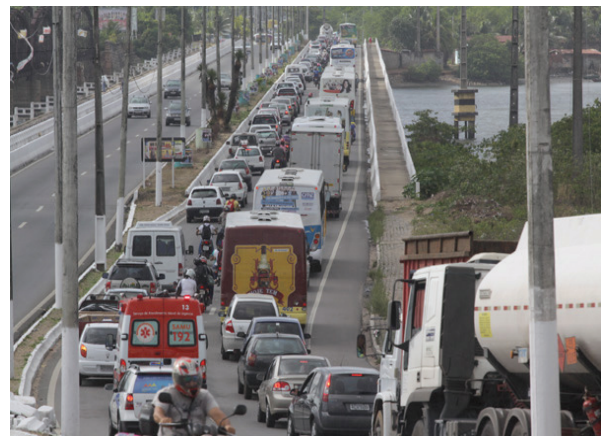

Figura 2. Congestionamento na "Ponte de Igapó".

Fonte: Tribuna do Norte: 04/09/2013.

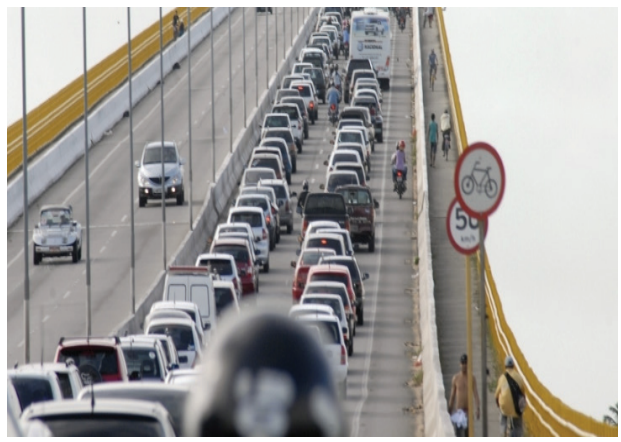

Figura 3. Congestionamento na Ponte Newton Navarro.

Fonte: Novo Jornal: 01/07/2014.

Desse modo, os congestionamentos se agravam uma vez que a região administrativa norte, a qual concentra pouco mais de $38 \%$ da população do município (SEMURB, 2012), é "separada" das demais pelo Rio Potengi (figura 4), "ligando-se" à região administrativa oeste pela "Ponte do Igapó" e à região administrativa leste pela Ponte Newton Navarro. E são justamente as regiões sul e leste as que concentram os maiores fluxos de comércio e demandas por serviços em Natal, portanto os eixos econômicos mais dinâmicos da cidade. 

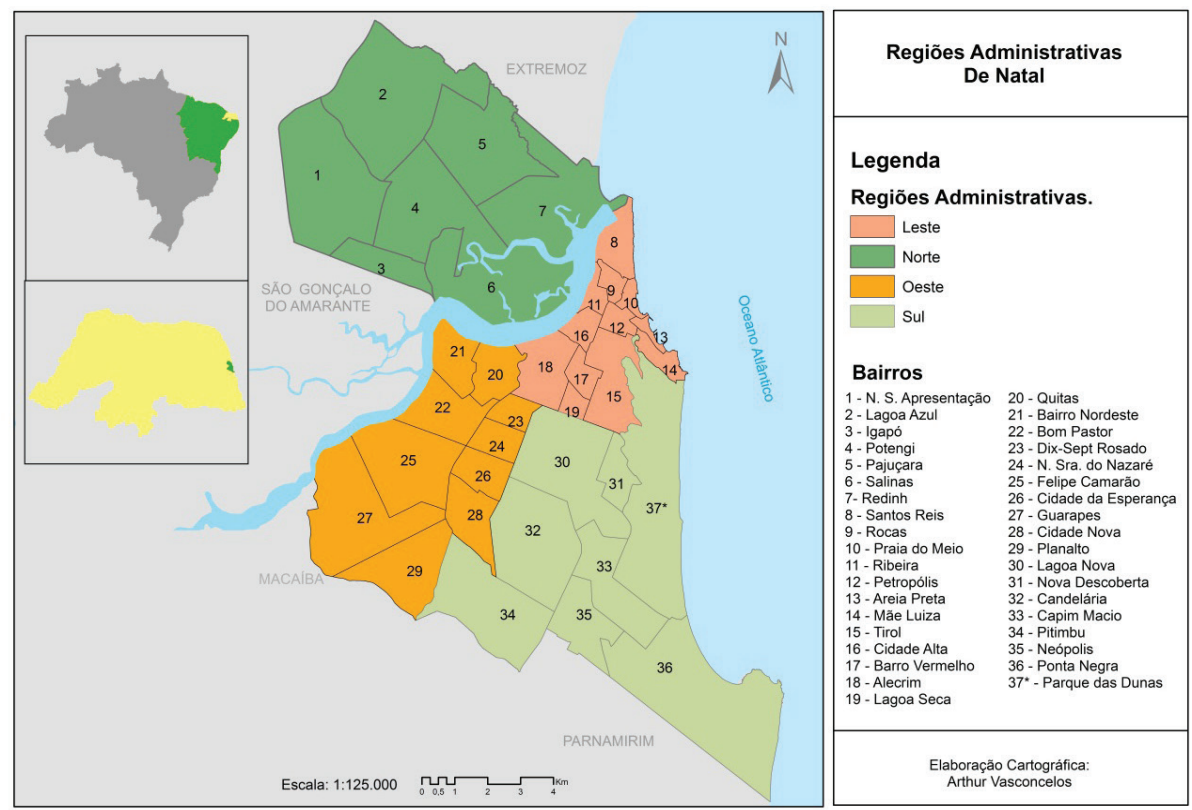

Figura 4. Localização do município de Natal.

Fonte: IBGE (2010)

A tabela 1 apresenta a evolução da frota total e da frota de automóveis referentes à Natal/RN e ao Brasil entre 2003 e 2013. O aumento acelerado da frota de veículos em Natal/RN segue a tendência da maioria das cidades brasileiras de grande e médio porte, sendo um dos fatores que tem provocado congestionamentos frequentes na cidade, apesar da construção/ampliação do sistema viário da cidade na primeira década do século XXI.

Nesse sentido, são exemplos da construção de sistemas viários em Natal o Complexo Viário Senador Carlos Alberto de Souza, conhecido como Viaduto do Quarto Centenário (inaugurado em 2000), localizado na Avenida Senador Salgado Filho; também nesta mesma avenida; a criação de um novo viaduto adjacente ao anterior, surgido como parte das obras realizadas em razão do megaevento mundial de futebol, a Copa do Mundo; também associado ao megaevento a construção de 3 túneis, sendo um que liga a Av. Romualdo Galvão à Avenida Norton Chaves e outros 2 que ligam a Av. Norton Chaves à Av. Lima e Silva e a Av. Prudente de Morais sucessivamente; interligase e associa-se a estas 4 últimas obras a construção de um viaduto na Av. Prudente de Morais, todas essas 5 últimas obras (3 túneis e 2 viadutos), construídos nas proximidades do Estádio Arena das Dunas como parte das obras surgidas em razão do megaevento Copa do Mundo de futebol, inaugurados em 2014, alguns inclusive inaugurados após o megaevento; acrescenta-se a este processo de ampliação viária da cidade na última década, a duplicação do Viaduto de Ponta Negra (inaugurado em 2007); a construção da Ponte Newton Navarro sobre a foz do Rio Potengi (inaugurada em 2007), ligando a Zona Norte às demais regiões da cidade; a construção do "Viaduto da Urbana"; a 
construção do Complexo Viário Ulisses de Góis (Túnel e Viaduto inaugurados em 2002), interligando as Avenidas Tomaz Landim, João Medeiros Filho e a Ponte Presidente Costa e Silva (Ponte de Igapó) na Zona Norte, dentre outros. No entanto, essas mesmas vias dotadas de novos objetos técnicos são, geralmente, aquelas que apresentam hoje os maiores congestionamentos na capital do estado, salvo algumas exceções, como é o caso das obras mais recentes.

Tabela 1. Evolução da frota total e da frota de automóveis ${ }^{1}$ para Natal/RN e para o Brasil (2003-2013).

\begin{tabular}{c|c|c|c|c}
\hline \multirow{2}{*}{ ANO } & \multicolumn{2}{|c|}{ BRASIL } & \multicolumn{2}{c}{ NATAL/RN } \\
\cline { 2 - 5 } & Frota total & $\begin{array}{c}\text { Frota de } \\
\text { automóveis }\end{array}$ & Frota total & $\begin{array}{c}\text { Frota de } \\
\text { automóveis }\end{array}$ \\
\hline 2003 & 36.658 .501 & 23.669 .032 & 162.893 & 111.749 \\
\hline 2004 & 39.240 .875 & 24.936 .541 & 171.833 & 116.884 \\
\hline 2005 & 42.071 .961 & 26.309 .256 & 180.757 & 121.491 \\
\hline 2006 & 45.372 .640 & 27.868 .564 & 194.495 & 129.440 \\
\hline 2007 & 49.644 .025 & 29.851610 & 213.727 & 139.731 \\
\hline 2008 & 54.506 .661 & 32.054 .684 & 235.159 & 150.354 \\
\hline 2009 & 59.361 .642 & 34.536 .667 & 255.817 & 160.995 \\
\hline 2010 & 64.817 .974 & 37.188 .341 & 279.301 & 171.467 \\
\hline 2011 & 70.543 .535 & 39.832 .919 & 299.929 & 180.445 \\
\hline 2012 & 76.137 .191 & 42.682 .111 & 320.081 & 190.717 \\
\hline 2013 & 81.600 .729 & 45.444 .387 & 339.429 & 200.312 \\
\hline
\end{tabular}

Fonte: dados adaptados do DENATRAN, 2014.

Ao adotar uma explicação coerente sobre o espaço no período técnico-científicoinformacional, Santos e Silveira (2008, p. 63) assinalam que "de um lado, os sistemas de objetos condicionam a forma como se dão as ações e, de outro lado, o sistema de ações leva a criação de objetos novos ou se realiza sobre objetos pré-existentes". Nesse sentido, em certa medida, a expansão das vias de circulação na cidade produz e é produto da expansão da frota de automóveis.

O que se nota é que, em Natal, a expansão das vias de circulação não tem sido suficiente para resolver o problema dos congestionamentos, ao menos em boa parte do tecido urbano, já que a frota de veículos tem crescido de forma acelerada, saturando rapidamente as novas vias construídas e/ou ampliadas.

O aumento dos congestionamentos, por sua vez, acaba dificultando a acessibilidade na cidade, isto é, "a relação entre o espaço a ser percorrido e os meios disponíveis para se realizar a locomoção, o que implica no tempo necessário para tal" (CARLOS, 2011, p.134). Nesse sentido, se um dos principais objetivos da compra do

1. O DENATRAN (2014) define automóvel como um "veículo automotor destinado ao transporte de passageiros, com capacidade para até oito pessoas, exclusive o condutor". A frota total inclui o número de automóveis somado ao número de outros veículos automotores: caminhões, ônibus, motocicletas, etc. 
veículo particular é aumentar a acessibilidade na cidade, o crescimento desenfreado da frota tem provocado justamente o contrário, uma vez que tem causado congestionamentos constantes e, consequentemente, diminuído a acessibilidade, aumentando o tempo de deslocamento tanto para quem utiliza o automóvel, quanto para quem necessita do transporte coletivo.

Em 2012, o IBGE publicou um estudo acerca do tempo de deslocamento da população para o trabalho nas capitais brasileiras evidenciando um percentual elevado de pessoas submetidas a longos intervalos de tempo entre a residência e o local de trabalho (Tabela 2).

Tabela 2: Tempo de deslocamento para o trabalho das pessoas que trabalham fora do local de domicílio e retornam diariamente para as suas residências (percentual no Brasil e em algumas capitais brasileiras - 2010).

\begin{tabular}{l|c}
\hline $\begin{array}{c}\text { Brasil e algumas capitais } \\
\text { estaduais }\end{array}$ & $\begin{array}{c}\text { Porcentagem da população cujo tempo de } \\
\text { deslocamento para o trabalho é superior a 1 hora }\end{array}$ \\
\hline Brasil & $11,40 \%$ \\
\hline São Paulo & $31,03 \%$ \\
\hline Rio de Janeiro & $25,34 \%$ \\
\hline Belo Horizonte & $16,55 \%$ \\
\hline Salvador & $22,03 \%$ \\
\hline Recife & $11,22 \%$ \\
\hline Fortaleza & $12,70 \%$ \\
\hline Natal & $8,76 \%$ \\
\hline Brasília & $16,49 \%$ \\
\hline Manaus & $17,34 \%$ \\
\hline Belém & $10,62 \%$ \\
\hline Curitiba & $10,84 \%$ \\
\hline
\end{tabular}

Fonte: adaptado do IBGE, 2012.

Depreende-se do exposto que o tempo de deslocamento para o trabalho em algumas capitais brasileiras é bastante elevado para um significativo número de trabalhadores, especialmente nas metrópoles com maior densidade populacional, a exemplo de São Paulo, Rio de Janeiro e Salvador. Em Natal/RN, 8,76\% dos trabalhadores demoravam mais de uma hora nos deslocamentos diários para o trabalho, em 2010 (IBGE, 2012). Boa parte dessa população reside na Zona Norte da cidade.

Não podemos afirmar categoricamente que o tempo de deslocamento maior ou menor para o trabalho nas cidades está relacionado exclusivamente à ocorrência de congestionamentos no trânsito, mas, certamente, há fatores que são próprios de cada cidade, como a estrutura viária e a localização das áreas de comércio e serviços, e outros que são comuns, como a ineficiência ou insuficiência do transporte público qualificado. Ressalta-se a importância de que essa pesquisa seja feita pelo IBGE periodicamente, relacionando essa informação com o aumento da frota de veículos nas referidas capitais. 
Em Natal, a solução apontada pelos gestores públicos para aumentar a fluidez tem sido a ampliação das vias de circulação existentes. Nesse sentido, foram elaborados novos projetos de expansão dessas vias, como a reestruturação da Avenida Engenheiro Roberto Freire, na Zona Sul da cidade; a reestruturação do sistema viário do entorno do estádio de futebol intitulado Arena das Dunas; a expansão da Avenida Prudente de Morais, interligada diretamente à BR-101, com o objetivo de diminuir o fluxo da Avenida Senador Salgado Filho e da BR-101; a construção do Corredor Estruturante Zona Norte-Estádio Arena das Dunas (MINISTÉRIO DAS CIDADES, 2013); a construção de um novo Complexo Viário no bairro Igapó (DIÁRIO OFICIAL DA UNIÃO, 2014), dentre outros.

Sabe-se que o crescimento da frota de automóveis demanda a expansão do sistema viário na cidade, porém, essa é cada vez mais difícil, bem como impactante social e ambientalmente, além de onerosa em função da intensa ocupação do solo, causando eliminação de áreas verdes (normalmente, como consequência pela supressão de canteiros e plantas das vias ampliadas), além de causar muitos transtornos à população atingida pelas desapropriações, quando é o caso.

Nesse sentido, outras medidas poderiam ser adotadas para preservar a acessibilidade das pessoas à cidade, como o investimento e o estímulo ao uso do transporte público, criação de um sistema integrado de ciclovias em toda a região metropolitana, melhorias na infraestrutura urbana, acesso aos espaços públicos e às vias de circulação (incluído capacidade de mobilidade), e diminuição dos incentivos públicos à aquisição de automóveis particulares por meio de subsídios. No entanto, a precariedade do transporte público, na maioria das grandes cidades, acaba tornando-se um dos fatores de estímulo à compra do carro próprio, o qual se torna objeto de desejo da maior parte da população.

\section{O sistema de transporte coletivo/público de Natal/RN}

O sistema de transporte coletivo/público em Natal é constituído, basicamente, pela frota de ônibus, mas também com um substrato de trens e transporte alternativo (micro-ônibus), ambos funcionando normalmente em precárias condições. Assim, o ônibus é a principal opção de locomoção para quem não dispõe de veículo particular, já que outros meios de transporte de massa na cidade são inexpressivos, seja em termos de número de linhas, portanto, de abrangência e acessibilidade aos vários bairros da cidade, seja em termos de disponibilidade de horários.

De acordo com Cruz (2012, p. 110-111), em estudo sobre o transporte público em Presidente Prudente/SP, o crescimento da frota de veículos particulares em circulação pode provocar a queda do IPK (Índice de passageiros por quilômetro rodado) do transporte público coletivo, devido à redução do número de usuários de ônibus. Nesse sentido, segundo a autora, as empresas buscam a manutenção das taxas de lucro, aumentando o preço da tarifa e minimizando os gastos com manutenção, provocando assim a deterioração do sistema de transporte público.

Em Natal, a modalidade de transporte coletivo (ônibus) apresenta uma série de problemas, como superlotações em horários de fluxo intenso, longo tempo de espera nas 
paradas, ônibus mal conservados, insegurança aos usuários e trabalhadores do sistema de transporte (motoristas e cobradores), falta de estrutura nos pontos de ônibus (paradas sem sinalização, sem abrigos ou proteção/conforto mínimo), associada à insegurança devido aos assaltos frequentes ocorridos nas paradas e no interior dos onibus etc.

Na última década, a única medida de "incentivo" à melhoria do transporte público em Natal foi a criação do sistema de integração/passe-livre, o qual permite que o usuário utilize dois ônibus para chegar ao seu destino, pagando uma única passagem (SECRETARIA MUNICIPAL DE MOBILIDADE URBANA DE NATAL - SEMOB, 2013), embora a construção da faixa exclusiva para ônibus numa única avenida da cidade, na Avenida Bernardo Vieira, também tenha corroborado incipientemente para uma melhoria pontual do sistema de transporte coletivo.

Além do ônibus, a população de quatro cidades da região metropolitana de Natal (Natal, Ceará-Mirim, Extremoz e Parnamirim) conta com o serviço de trens urbanos. A ferrovia é composta por duas linhas (a norte, que liga Ceará-Mirim a Natal, e a sul, ligando Parnamirim a Natal) numa extensão total de $56 \mathrm{~km}$.

Porém, os trens urbanos são pouco utilizados pela população, uma vez que o número de usuários/dia chega a 8.482 (COMPANHIA BRASILEIRA DE TRENS URBANOS - CBTU, 2013), o que corresponde a uma parcela insignificante se comparado ao número de usuários de ônibus em Natal e região metropolitana (aproximadamente 500.000). Mesmo cobrando uma tarifa muito barata ( $\mathrm{R} \$ 0,50$ - cinquenta centavos de real), o serviço de trens urbanos não apresenta uma demanda significativa no sistema de transporte público na cidade.

Essa situação ocorre devido a diversos fatores, como a pouca disponibilidade de horários, com reduzido número de viagens, deterioração no estado de conservação das locomotivas, as quais muitas estão em uso há mais de 50 anos. Os trajetos dos trens e as rotas das ferrovias percorrem justamente a periferia das cidades assistidas até chegar ao bairro da Ribeira, na Zona Leste de Natal, outrora um dos principais centros comerciais, porém, hoje com pouco dinamismo econômico e reduzidos fluxos ligados aos serviços e comércio.

Além disso, as estações de desembarque ao longo dos percursos, geralmente, ficam distantes dos principais centros de fluxos de pessoas, a exemplo dos centros comerciais e de consumo, shoppings centers, escolas, universidades, templos religiosos, estádios de futebol etc., que se concentram, principalmente, em bairros das Zonas Sul e Leste de Natal. Com isso, a maior parte da população da periferia faz opção pelo ônibus, que apresenta maior flexibilidade de horários e de paradas, além de dispor de percursos mais extensos.

Recentemente, o sistema de transporte ferroviário da região metropolitana de Natal foi incluído no programa do Governo Federal, o PAC da Mobilidade Urbana. De acordo com a CBTU (2013), o projeto contempla "a aquisição de 12 composições de VLT, 02 locomotivas, trilhos e dormentes para a modernização de sua via permanente", o que pode viabilizar o aumento do número de usuários do sistema.

No entanto, no caso dos trens urbanos, a medida, que implicará, sobretudo, a troca de locomotivas, não acarretará melhorias significativas nessa modalidade de 
transporte público em Natal e no seu entorno, pois sem a ampliação das linhas, de modo que possa atender aos possíveis usuários num raio mais diverso e abrangente e de maior fluxo, o impacto positivo será pouco significativo. Outro problema diz respeito à falta de integração entre ambas as modalidades, isto é, entre o trem e o ônibus, pois, por enquanto, o projeto não prevê essa medida, o que pode se constituir como fator limitante e que implicará em reduzida eficácia da proposta.

Além das opções pelas modalidades ônibus e trem, o serviço de transporte coletivo de Natal é complementado pelo transporte alternativo/opcional. Cada veículo (micro-ônibus) tem capacidade para 16 usuários sentados (SEMOB, 2013), embora, normalmente, apresente superlotação que, às vezes, compromete a segurança do usuário.

O transporte opcional tornou-se uma alternativa aos ônibus, uma vez que circula por vias que não são atendidas por esse meio de transporte. Percebemos que os problemas enfrentados pelos usuários desse tipo de transporte são semelhantes aos dos usuários de ônibus, com um agravante: até recentemente (2014), o pagamento da passagem, tanto do ônibus quanto do alternativo, era feito principalmente por meio da bilhetagem eletrônica. Porém, ao fazer a recarrega do cartão de passagens (bilhete eletrônico), o usuário devia escolher entre fazer a recarrega para ônibus ou para o transporte alternativo (opcional), embora a tarifa fosse a mesma ( $\mathrm{R} \$ 2,35$ - dois reais e trinta e cinco centavos) em ambas as modalidades. Como a frota e a capacidade dos ônibus são maiores, em relação ao transporte alternativo, a maior parte da população faz opção pelo primeiro, sujeitando-se às empresas que detêm a concessão dos ônibus, conforme observado no quadro 1 .

Quadro 1. Quadro comparativo do transporte público em Natal/RN (2013).

\begin{tabular}{l|c|c|c|c|c|c|c}
\hline $\begin{array}{l}\text { Meio de } \\
\text { transporte } \\
\text { público }\end{array}$ & Tarifa & $\begin{array}{c}\text { Linhas } \\
\text { em } \\
\text { operação }\end{array}$ & Frota & $\begin{array}{c}\text { Número de } \\
\text { empresas }\end{array}$ & $\begin{array}{c}\text { Passageiros/ } \\
\text { Dia }\end{array}$ & $\begin{array}{c}\text { Número } \\
\text { viagens/ } \\
\text { Dia }\end{array}$ & $\begin{array}{c}\text { Idade } \\
\text { média da } \\
\text { frota }\end{array}$ \\
\hline Ônibus & $\mathrm{R} \$ 2,35$ & 86 & 712 & 6 & 530.000 & 7.903 & 7,51 anos \\
\hline $\begin{array}{l}\text { Veículo } \\
\text { alternativo }\end{array}$ & $\mathrm{R} \$ 2,35$ & 24 & 177 & $\begin{array}{c}\text { Não } \\
\text { disponível }\end{array}$ & $\begin{array}{c}\text { Não } \\
\text { disponível }\end{array}$ & $\begin{array}{c}\text { Não } \\
\text { disponível }\end{array}$ & $\begin{array}{c}\text { Não } \\
\text { disponível }\end{array}$ \\
\hline $\begin{array}{l}\text { Transporte } \\
\text { ferroviário }\end{array}$ & $\mathrm{R} \$ 0,50$ & $\mathrm{X}$ & $\mathrm{X}$ & $\mathrm{X}$ & 8.482 & 12 & $\begin{array}{c}\text { Frota da } \\
\text { década de } \\
1950\end{array}$ \\
\hline
\end{tabular}

Fonte: Adaptado de CBTU, 2013; SEMOB, 2013.

Depreende-se que, apesar de todos os problemas que se observa quando se faz uma análise comparativa, o ônibus aparece como o meio de transporte mais significativo na capital do Rio Grande do Norte, na medida em que possui a maior frota, transporta uma maior quantidade de passageiros e, consequentemente, realiza um maior número de viagens em relação ao trem e ao transporte alternativo, não obstante todas as fragilidades existentes nesse sistema de transporte conforme apontado anteriormente. 


\section{Considerações finais}

A expansão das principais vias de circulação em Natal/RN, visando garantir maior capacidade de fluidez à cidade, tem se constituído em ações paliativas e refletem as contradições que marcam o processo de produção do espaço urbano no mundo subdesenvolvido, onde, normalmente, não se adota medidas estruturantes de médio e longo prazo, buscando alternativas viáveis que propiciem a melhoria das condições de vida e de habitat da coletividade e da maioria da população, mas de uma minoria privilegiada que detém maior poder de compra, portanto, maior capacidade de consumo. As medidas adotadas não têm sido suficientes para tornar mais eficaz a acessibilidade aos distintos espaços da cidade, embora beneficiem sobretudo, aqueles espaços mais densos em técnica, em investimentos públicos e privados, portanto, com maior dinamismo mercantil e econômico.

Faz-se necessário, além da ampliação das vias de circulação, maior investimento por parte do poder público, visando melhorias na qualidade do transporte público, combinando agilidade, diversificação, conforto, segurança, maior frequência de horários, portanto, maior incentivo ao seu uso.

É importante considerar ainda que a reestruturação e a melhoria do sistema ferroviário, incluindo a implantação do VLT (Veículo Leve sobre Trilhos) pode vir a ser uma alternativa viável para melhor atender a demanda social existente, obviamente partindo do princípio da integração entre trem, ônibus e transporte alternativo, acompanhada de medidas de segurança aos usuários do transporte público, além da construção de abrigos (pontos de parada e de integração) com segurança, proteção, iluminação e sinalização, tudo isso como forma de estímulo a uma maior utilização desse sistema e, consequentemente, diminuição no número de veículos nas ruas, o que seria menos oneroso economicamente à população e ao poder público, bem como mais viável do ponto de vista socioambiental. Associado a isso carece ainda a criação de um sistema integrado de ciclovias na capital e em seu entorno, garantindo segurança, barateamento no custo de locomoção e liberdade de escolha dentre as alternativas de transporte existentes, além de se constituir numa prática que vem a favorecer a saúde do usuário desse sistema.

\section{Referências}

ANFAVEA - ASSOCIAÇÃO NACIONAL DOS FABRICANTES DE VEÍCULOS AUTOMOTORES DO BRASIL. Anuário da Indústria Automobilística Brasileira 2014. Disponível em: <http://www.anfavea.com.br/anuario.html $>$. Acesso em $21 \mathrm{de}$ jun. 2014.

ARBIX, Glauco. Guerra Fiscal e Competição Intermunicipal Por Novos Investimentos no Setor Automotivo Brasileiro. Revista de Ciências Sociais, vol.43 n.1, IUPERJ, Rio de Janeiro, julho de 2000.

CARLOS, Ana Fani Alessandri. A (Re)Produção do Espaço Urbano. 1ed., 1. Reimpressão. São Paulo. Editora da Universidade de São Paulo, 2008. 
. Da "Organização" à "Produção" do Espaço no Movimento do Pensamento Geográfico. In: CARLOS, Ana Fani Alessandri; Et al. (orgs). A Produção do Espaço Urbano: Agentes, Processos, Escalas e Desafios. São Paulo: Contexto, 2011.

COMPANHIA BRASILEIRA DE TRENS URBANOS - CBTU. CBTU Natal Estatísticas. Disponível em: <http://natal.cbtu.gov.br/estatistica/natsist/slide23.htm $\geq$. Acesso em 04 de mar. 2013.

Chegada do VLT impulsiona o desenvolvimento da Região Metropolitana

de Natal. Disponível em: <http://www.cbtu.gov.br/noticias/destaques/2013/ mes02/260213a/260213a.html> Acesso em: 04 mar. 2013.

CORRÊA, Roberto Lobato. O Espaço Urbano. 1. Ed. São Paulo: Ática,1989.

CRUZ, Dayana Aparecida Marques de Oliveira. Transporte público coletivo em Presidente Prudente: planejamento, mobilidade e acessibilidade no consumo do espaço urbano. Presidente Prudente. UNESP 2012, 171 f. Dissertação Universidade Estadual Paulista, Faculdade de Ciências e Tecnologia, Presidente Prudente, 2012.

DENATRAN, Departamento Nacional de Trânsito. Frota. Disponível em: <http:// www.denatran.gov.br/frota.htm>. Acesso em: 13 abr. 2014.

DIÁRIO OFICIAL DA UNIÃO. Aviso De Licitação. Rdc Eletrônico No 34/2014 - Uasg 393021. Disponível em: <http://www.jusbrasil.com.br/diarios/65614772/dousecao-3-04-02-2014-pg-138 $\geq$ Acesso em: 23 jun. 2014.

INSTITUTO BRASILEIRO DE GEOGRAFIA E ESTATÍSTICA - IBGE. Sistema IBGE de Recuperação Automática. Censo Demográfico. 2010. Disponível em: http:// www.sidra.ibge.gov.br/

Tempo habitual de Deslocamento para o Trabalho de Pessoas Que Trabalhavam Fora do Domicílio e Retornavam Para Seu Domicílio Diariamente (Percentual) (2010) Disponível em: < http://www.ibge.gov.br/home/pesquisa/pesquisa google.shtm?cx=009791019813784313549\%3Aonz63jzsr68\&cof=FORID\%3A9\&ie= SO-8859-1\&q=Tempo + habitual + de + Deslocamento + para + o + Trabalho + de + Pessoas $+Q$ ue + Trabalhavam + Fora + do + Domic $\%$ EDlio + e + Retornavam + Para + Seu + Domic $\%$ EDlio + Diariamente $+\% 28$ Percentual $\% 29+\% 282010 \% 29+\& s a=$ Pesquisar\&siteurl=www.ibge. gov.br\%2Fhome\%2F\&ref=www.ibge.gov.br\%2F\&ss=0j0j2>. Acesso em: 13 abr. 2013.

MINISTÉRIO DAS CIDADES. Mobilidade Urbana. Disponível em: < http://www. pac.gov.br/cidade-melhor/mobilidade-urbana> Acesso em: 09 abr. 2013.

NATAL, Prefeitura Municipal do Natal, SEMOB - Secretaria Municipal de Mobilidade Urbana de Natal. Ônibus. Disponível em: <http://portal.natal.rn.gov.br/sttu2/paginas/ ctd-709.html> Acesso em: 11 jul. 2013.

. Opcionais. Disponível em: $\leq$ http://portal.natal.rn.gov.br/sttu2/paginas/ctd-710. html> Acesso em: 11 jul. 2013.

. Passe Livre. Disponível em: <http://portal.natal.rn.gov.br/sttu2/paginas/ctd728.html> Acesso em: 11 jul. 2013. 
. SEMURB - Secretaria Municipal de Meio Ambiente e Urbanismo. Anuário Natal 2011-2012. Natal - RN: SEMURB, 2012. 402p.

. SEMURB - Secretaria Municipal de Meio Ambiente e Urbanismo. Conheça melhor o seu Bairro: Lagoa Nova. Natal: Departamento de Informação, Pesquisa e Estatística, 2008.

SANTOS, Ana Matilde Vasconcelos do Nascimento; As Transformações do Espaço Urbano de Natal (RN) Correlacionadas aos Preparativos Para o Megaevento Copa do Mundo (2014) - Brasil. Natal (RN). UFRN 2014, 168 f. Dissertação Universidade Federal do Rio Grande do Norte. Programa de Pós-Graduação em Turismo - PPGTUR. Natal, 2014.

SANTOS, Milton; SILVEIRA, Maria Laura. Brasil, Território e Sociedade no Início do Século XXI 10. Ed. Rio de Janeiro: Record, 2008.

NOVO JORNAL. Semob viabiliza estudo para a construção de uma nova ponte. < http://www.novojornal.jor.br/noticias/cidades/437>. Acesso em $11 \mathrm{dez} .2014$.

TRIBUNA DO NORTE. Rodoviários param em protesto à violência após quase 200 assaltos. Disponível em: <http://tribunadonorte.com.br/noticia/rodoviarios-param-emprotesto-a-violencia-apos-quase-200-assaltos/280131> Acesso em 23 jun. 2014.

. Sinduscon Propõe Ampliar Ponte. Disponível em: $<$ http://tribunadonorte.com. br/noticia/sinduscon-propoe-ampliar-ponte/247205> Acesso em $11 \mathrm{dez} .2014$.

Francisco Fransualdo de Azevedo

Doutor em Geografia pela Universidade Federal de Uberlândia. Atualmente é Professor do Departamento de Geografia da Universidade Federal do Rio Grande do Norte e Docente Permanente dos Programas de Pós-Graduação em Geografia e Turismo.

UFRN, Campus Universitário Lagoa Nova - CCHLA - Av. Salgado Filho. Lagoa Nova. Cep: 59072-970 - Natal, RN - Brasil - Caixa-postal: 1524.

E-mail: ffazevedo@gmail.com

Leonardo da Silva Galindo

Graduando em Geografia pela Universidade Federal do Rio Grande do Norte.

UFRN, Campus Universitário Lagoa Nova - CCHLA - Av. Salgado Filho. Lagoa

Nova. Cep: 59072-970 - Natal, RN - Brasil - Caixa-postal: 1524.

E-mail: leonardogalindo.ufrn@gmail.com

Recebido para publicação em fevereiro de 2015 Aprovado para publicação em maio de 2015 